\title{
Aproximación al paisaje lingüístico de Málaga: Préstamos y reflejos de una realidad lingüística plural
}

Diana Esteba Ramos

\section{CpenEdition}

\section{Journals}

Edición electrónica

URL: https://journals.openedition.org/cher/7340

DOI: $10.4000 /$ cher.7340

ISSN: 2803-5992

Editor

Presses universitaires de Strasbourg

Edición impresa

Fecha de publicación: 7 julio 2014

Paginación: 165-187

ISBN: 978-2-86820-569-8

ISSN: 1968-035X

\section{Referencia electrónica}

Diana Esteba Ramos, «Aproximación al paisaje lingüístico de Málaga: Préstamos y reflejos de una

realidad lingüística plural», reCHERches [En línea], 12 | 2014, Publicado el 13 diciembre 2021,

consultado el 15 diciembre 2021. URL: http://journals.openedition.org/cher/7340 ; DOI: https:// doi.org/10.4000/cher.7340

\section{cc) (1) (5)}

Ce(tte) œuvre est mise à disposition selon les termes de la Licence Creative Commons Attribution Pas d'Utilisation Commerciale - Partage dans les Mêmes Conditions 4.0 International. 


\title{
Aproximación al paisaje lingüístico de Málaga: Préstamos y reflejos de una realidad lingüística plural
}

\author{
Diana Esteba Ramos \\ Universidad de Málaga
}

$\mathrm{H}$ ablar del estudio del Paisaje Lingüístico (en adelante, PL) de nuestras ciudades implica volver la vista al trabajo de Landry y Bourhis (1997) y a algunos otros textos posteriores, como los de Gorter (2006) o Backhaus (2007), con los que se lleva a cabo una reflexión metodológica y unas primeras tentativas de aplicación que sirven de base para una cada vez más abundante nómina de estudios sobre los signos lingüísticos públicos de diversas ciudades: Jerusalén (Ben-Rafael 2006), Tokio (Backhaus 2007), Los Ángeles (Franco Rodríguez 2008), Sevilla (Pons)... ${ }^{1}$

Estos y otros estudios ponen en evidencia que a través del PL se analiza especialmente la copresencia de varias lenguas como índice de vitalidad de los grupos de población que existen en un territorio dado: así se han analizado espacios bilingües como Quebec o Bélgica y, de hecho, en España sus trabajos han fijado la mirada en primer lugar en territorios bilingües como el País Vasco o Cataluña, para continuar posteriormente con regiones donde el bilingüismo no fuera una realidad oficial ${ }^{2}$. En efecto, en espacios monolingües se manifiestan trazas de otras lenguas: con función básicamente simbólica, a través de la rotulación comercial, por ejemplo; o fundamentalmente informativa, en variedad de signos surgidos como

1 Es posible encontrar antecedentes en Masai (1972), sobre la presencia del inglés en la ciudad de Tokio; Tulp (1978), sobre la posición del francés en Bruselas; o Spolsky y Cooper (1991), en torno al PL de Jerusalén.

2 Urrutia (1999) y Cenoz y Gorter (2006) dedican sus estudios al País Vasco, mientras que en Solé (1998) y Leprête y Romaní (2000) se analiza el caso catalán. 
consecuencia de la globalización o de las corrientes turísticas y de migración que se desarrollan en los países. La consecuencia es la observación de interesantes muestras lingüísticas teñidas de convergencia, préstamos o calcos en prácticamente todas las ciudades del mundo.

\section{Estudio}

\section{Objetivos}

Es un hecho que, en nuestros días, solo los lugares realmente aislados recrean un PL verdaderamente monolingüe. Por ello, nuestro objetivo aquí es analizar un territorio oficialmente monolingüe, Málaga, pero plurilingüe de facto, donde lenguas y variedades se superponen y acompañan, se prestan recursos y procedimientos para conformar un paisaje plural y heterogéneo. Se trata, además, de una zona que no ha sido analizada a través de una metodología semejante 3 .

Este primer análisis que presentamos es en realidad una pequeña cala que busca resolver ciertos interrogantes metodológicos y plasmar algunas realidades ${ }^{4}$. En último término, asimismo, nos encargaremos de presentar algunas aplicaciones docentes que hemos llevado a cabo con el PL en el ámbito del español normativo ${ }^{5}$.

3 Varios investigadores del grupo VUM de la Universidad de Málaga han analizado el español de esta ciudad desde diferentes perspectivas. Una visión de conjunto reciente se obtiene en la publicación colectiva editada por Villena Ponsoda y Ávila Muñoz (2012). Llegado el caso, las investigaciones que nos animamos a comenzar podrían servirse de estas publicaciones y complementarlas para conformar una visión más integradora de la realidad lingüística malagueña, dentro de las hablas andaluzas.

4 Eso sí, quedan aún muchas otras cuestiones por resolver a las que no hemos buscado dar respuesta en estas líneas, tales como dónde establecer los límites entre lo público y lo privado, cómo se conectan estos signos con las personas, cómo interactúan con las imágenes...

5 Esta contribución se inserta en un proyecto mayor que se encuentra aún en estado inicial, pero que aspira a tener como objetivo final la caracterización del PL malagueño además del cuestionamiento de ciertas cuestiones teórico-metodológicas (los primeros frutos se pueden ver en D. Esteba Ramos [en prensa]). Nos interesarían colateralmente, asimismo, poblaciones de la provincia, que podrían ayudar a obtener datos que sirvieran para contextualizar aquellos recabados en la capital. La realidad es que muchos municipios malagueños tienen un alto porcentaje de extranjeros entre sus vecinos, que se convierten en destinatarios y creadores de signos de gran interés (por ejemplo, en Fuengirola, localidad de la costa malagueña, hay un $34 \%$ de extranjeros censados). No de menos importancia resulta la población itinerante que gracias al turismo o las estancias de formación académica recibe tanto la capital como otras poblaciones. 


\section{Metodología}

Hemos utilizado una cámara de fotos digital compacta Sony Cyber-shot con la que hemos fotografiado durante los meses de marzo y abril de 2012 un sector del centro de Málaga, que encuentra sus límites en la plaza de la Merced y calle Madre de Dios, al norte; al sur, en la plaza de Uncibay; en calle Carretería al oeste y en calle Alcazabilla al este, es decir, una parte pequeña pero representativa del centro de la ciudad. Además, hemos tomado muestras aleatorias en otras zonas del centro.

Para reducir los problemas derivados de la ausencia de exhaustividad y del carácter efímero del objeto de estudio, decidimos hacer un barrido lo más sistemático posible de esta zona durante un par de meses: preferimos, por ello, decantarnos por un espacio concreto del centro de la ciudad (complementado con las muestras aleatorias), que nos permitiera hacer hipótesis de lo que podríamos encontrar en un estudio posterior. Se trata de un espacio conformado por vías comerciales principales, conjuntos monumentales, edificios públicos y vías secundarias de transición a zonas socialmente deprimidas y de origen multiétnico. Es un área turística, pero, además, según los datos del padrón de 2011, el distrito centro es el que más población extranjera tiene empadronado: aproximadamente el 12\% de los censados, de los que un $9 \%$ son no comunitarios 6 . Es, a la vez, un lugar cohabitado por habitantes de diversos estratos socioculturales. Buscamos, así, caracterizar a habitantes y visitantes de la zona, aunque somos conscientes de que no todos los hablantes alfabetizados dejan huella en el PL de algunos lugares.

En cualquier caso, la zona se define por ser punto de encuentro de extranjeros de diversas nacionalidades. Por ello, esperamos encontrar varios de los patrones recurrentes descritos por Castillo Lluch y Sáez Rivera (2011): monopoly, el patrón típico de las calles prestigiosas con usos de lenguas extranjeras con valor connotativo en la rotulación o denotativo en los carteles para turistas; variante progresiva o boca del lobo, esto es, el que caracteriza a las calles que van poco a poco transformando la presencia de lenguas; moteado, el que presenta dispersión por toda la ciudad.

Hemos tomado muestras de signos que estuvieran parcial o íntegramente escritos en una lengua diferente al español o que presentaran fenómenos de contaminación lingüística o dialectal. A pesar de las limitaciones

6 Padrón de la ciudad de Málaga 2012, http://gestrisam.malaga.eu/export/sites/default/ economia/gestrisam/portal/menu/seccion_0006/documentos/2012_poblacion_extranjera.pdf 
metodológicas de las que éramos conscientes antes de acometer la recogida de datos y del espacio reducido seleccionado para la toma de muestras, hemos trabajado con un corpus de más de 220 fotografías que hemos catalogado en una tabla Excel donde se recogían los siguientes apartados de análisis, deudores de los de Backhaus (2007: 66-67):

- tipología del signo

- lenguas en el signo

- prominencia visual de la lengua

- disponibilidad de traducción total o parcial

- carácter eminentemente simbólico o informativo del signo

- idiosincrasias lingüísticas

Además, hemos trabajado con los propios textos de los signos, es decir, gracias a un programa de concordancias hemos analizado cuáles son sus términos más recurrentes.

\section{Análisis de los datos}

En primer lugar, hemos tenido que enfrentarnos a la determinación de los límites del signo utilizado en el PL. En efecto, ello dependerá de la interpretación que queramos dar a definiciones canónicas como las de Backhaus (2006: 55), para quien es «any piece of written text within a spatially definable frame». Ese marco espacial aludido admite diversas interpretaciones que nos van a llevar a considerar más o menos ítems de análisis. Creemos que según las finalidades de cada estudio se deben preestablecer los límites ad hoc. Así, en nuestro caso, hemos incluido como un solo signo el que compartiera claramente un único soporte material y, en caso de dudas, hemos considerado dos. No hemos atendido a la densidad: es decir, no hemos contado separadamente un cartel que aparece repetido.

Lo cierto es que a esta dificultad se añade el que al analizar estos ítems de manera aislada se da el mismo valor a un cartel minúsculo y a uno inmenso, pero por el momento no hemos creído fundamental introducir esta marca en nuestro análisis: eso sí, hemos desechado signos móviles (vehículos, vestuario de ciudadanos...) y carteles demasiado pequeños (como menús) que no son visibles a distancia media.

Relacionado con la determinación del responsable o responsables del signo, se encuentra en ocasiones la imposibilidad de localizar al creador del mensaje o, en palabras de Franco Rodríguez, al iniciador: en nuestra sociedad globalizada, muchas de las rotulaciones se usan en todo el planeta, lo que no contribuye a determinar las características propias de un PL 
local. En consecuencia, para conseguir unos resultados más conformes con la verdadera radiografía lingüística de la ciudad que nos concierne, no hemos tenido en cuenta las vallas publicitarias, puesto que la mayor parte de los signos allí recogidos son mensajes globalizados, idénticos en todo el país o incluso en varios países. No obstante, aunque pueda entrañar cierta contradicción con la determinación que acabamos de exponer, sí hemos tomado los carteles de las franquicias encontradas en nuestra zona.

\section{Tipología del signo}

Los signos estudiados por el PL son aquellos que aparecen en el espacio público, un área que tiende a ser absorbida principalmente por el capitalismo y la comercialización, aunque también da cabida a la contestación a través de grafitis y otros textos reivindicativos o de protesta ${ }^{7}$. En esta área, no todas las instituciones, organizaciones y diferentes responsables de textos públicos son igualmente visibles y, además, su visibilidad puede ser muy cambiante, es decir, forma parte de un escenario que se hace y rehace constantemente.

Los actores sociales generan textos susceptibles de ser estudiados dentro de una tipología variada. En nuestro caso, hemos preferido partir de una clasificación ad hoc (incluye solo tipos adecuados a las muestras que hemos tomado), deudora parcialmente de Spolsky y Cooper (1991) y FrancoRodríguez (2009).

\begin{tabular}{|l|l|}
\hline \multicolumn{1}{|c|}{$\begin{array}{c}\text { Textos creados por ciudadanos } \\
\text { en tanto que ciudadanos }\end{array}$} & \multicolumn{1}{|c|}{ Grafitis, anuncios, nombres de casas } \\
\hline $\begin{array}{l}\text { Textos comerciales, creados por ciuda- } \\
\text { danos en tanto que trabajadores de } \\
\text { comercios o contratados por estos }\end{array}$ & $\begin{array}{l}\text { Nombres de locales comerciales, nombres de locales } \\
\text { comerciales que incluyen información sobre la actividad } \\
\text { económica que se desarrolla, otros textos en papel o pi- } \\
\text { zarra }\end{array}$ \\
\hline $\begin{array}{l}\text { Textos institucionales, creados por ciu- } \\
\text { dadanos en tanto que trabajadores de } \\
\text { instituciones o contratados por estas }\end{array}$ & Información turística \\
\hline Otros & Alcantarillas, pegatinas \\
\hline
\end{tabular}

7 Ben-Rafael (2009: 40). La definición de la esfera pública (el espacio público) ha sido uno de los caballos de batalla en la teoría de la sociedad moderna. Partiendo de las reflexiones de Habermas, se ha analizado la importancia de las diversas implicaciones de este término en relación con las sociedades que lo construyen (Eder 2005).

8 La propuesta de clasificación es ad hoc, como decimos, y sería necesario trabajar con más volumen de signos para aspirar a proponer una tipología propia. De hecho, pensamos que es necesario, ya que, como indica Huebner (2006), no están bien definidos los géneros que le ocupan al PL y ello podría ser una futura vía de investigación, a la que seguramente habría que añadir ámbitos. Además, como sugiere la clasificación de Barni y Bagna (2009), es necesario establecer tipologías abiertas que puedan reestructurarse según los estudios concretos llevados a cabo. 
Para configurar las diferencias entre los tipos, hemos partido de la consideración de los siguientes componentes:

a) Agente social implicado en la creación: ciudadanos, agente comercial, agente institucional. Cuando ha sido pertinente hemos distinguido el iniciador del creador: considerar estas dos figuras nos ayuda a contemplar el proceso de creación del PL en su totalidad, comprendiéndolo en su complejidad ${ }^{9}$. El iniciador/propietario del signo puede ser diferente del que lo materializa: de esta confrontación, se extraen consecuencias de gran interés. Es lo que ocurre en las fotos 1,2 y 3 de un mismo negocio, en el tercero es realizado seguramente por una persona contratada por los propietarios para tal fin, diversa a los textos más directos de 1 y 2 . De la comparación de estos signos concluimos que ciertas características lingüísticas relacionadas con la hibridación de variedades fonético-fonológicas locales y generalistas transferidas al escrito, interferencia de lenguas o incorrecciones ortográficas («crisi» por «crisis» en 2; «my» por «mi» en 1; «atun» por «atún» en 1 y 3 ) desaparecen cuando el responsable del texto no es el propietario o empleado del negocio, que no muestra a veces tanto cuidado en la escritura como el profesional ${ }^{10}$.

b) Carácter profesional / no profesional, que suele ir asociado al soporte: cuanto menos profesional, más efímero y menos presión de corrección lingüística. Los anuncios manuscritos son un estupendo índice de vitalidad efectiva de las lenguas. En efecto, los carteles privados en general no son cuidadosamente editados y dan cuenta de una ortografía particular. Es ahí donde hemos encontrado las interferencias lingüísticas.

c) Soporte: pared, pizarra, papel, papel-cartel, otros.

d) Carácter eminentemente simbólico o informativo, aspecto que trataremos con más detenimiento más adelante

e) Presencia del signo en el exterior (outdoor) o en el interior (indoor): en nuestro caso, solo hemos trabajado con los outdoor, ya que son más visibles y en un estudio aproximativo como éste era nuestro objetivo.

9 Incluso así estamos llevando a cabo una simplificación, ya que en la conformación del PL hay que contar con una cantidad variable de actores con motivaciones y horizontes variados, con diferente control sobre el resultado final del signo (Malinowski 2009). Es necesario pensar en figuras diversas tales como diseñadores profesionales, empleados públicos, trabajadores de diversos comercios y ciudadanos de a pie, entre otros.

10 Es cierto que también hemos encontrado errores en textos profesionales, pero suelen ser menos frecuentes. 
En general, los signos con muestras en otras lenguas que más hemos encontrado son textos comerciales.
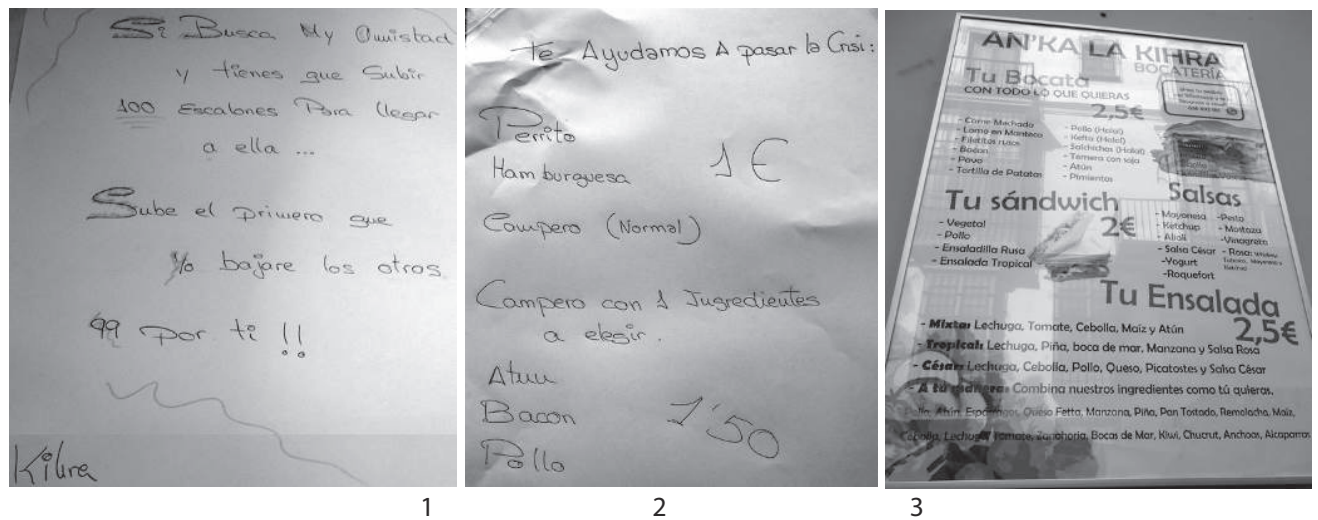

Lenguas en el signo

La mayor parte del paisaje de la ciudad presenta ejemplos de la lengua nacional, el español, algunos de lenguas extranjeras (aunque en algunos casos se trate solo de nombres propios) y prácticamente ninguno de lengua regional. Los datos se recogen en la siguiente tabla:

\begin{tabular}{|l|c|}
\hline \multicolumn{1}{|c|}{ Lengua } & Número de signos en los que aparece \\
\hline Inglés & 157 \\
\hline Italiano & 22 \\
\hline Francés & 15 \\
\hline Ruso & 7 \\
\hline Árabe & 6 \\
\hline Chino & 5 \\
\hline Alemán & 5 \\
\hline Catalán & 2 \\
\hline Neerlandés & 2 \\
\hline Latín & 2 \\
\hline Lenguas escandinavas & 2 \\
\hline Griego & 1 \\
\hline Hindi & 2 \\
\hline Hebreo & 1 \\
\hline Japonés & 1 \\
\hline
\end{tabular}

Como vemos, se reflejan quince lenguas además del español en la zona analizada. Siete de ellas son lenguas nacionales en la Unión Europea y otras seis lo son fuera de ella. Además, encontramos ejemplos también de una 
lengua muerta: el latín (5). En cuanto a las lenguas regionales presentes, solo hemos hallado datos para el catalán $(4)^{11}$.
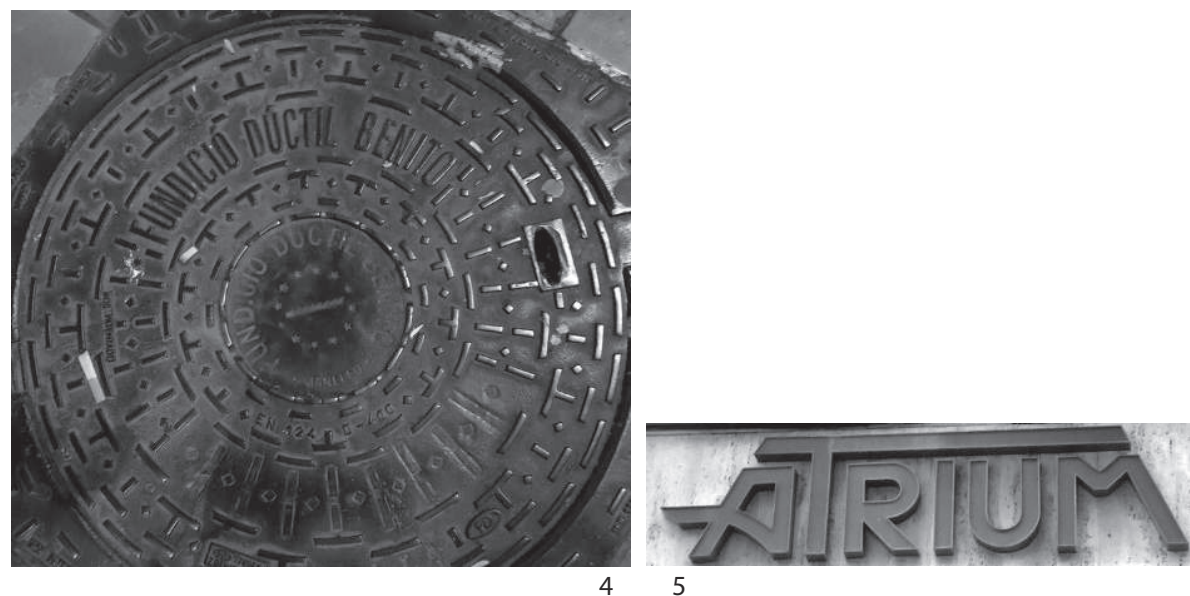

El inglés domina sobre todas las lenguas registradas: en efecto, es una lingua franca no ascendida a tal estatus por ninguna legislación pero, como ya han mostrado estudios en Madrid, Sofía, Roma, Estrasburgo, Sevilla y otras ciudades ${ }^{12}$, se usa por todo el mundo. Además, junto con el alemán y el francés, es la lengua más promocionada en la UE. No obstante, en nuestra muestra el italiano se encuentra por delante de estas dos lenguas, fundamentalmente por los valores simbólicos que conlleva, como veremos a continuación.

11 Extra y Gorter (2008). Podría decirse que nuestros datos se corresponden con la realidad propiciada en el seno de la UE, en tanto en cuanto la pluralidad lingüística es considerada una propiedad clave de la identidad europea y en la política lingüística de las Instituciones Europeas figura la promoción del aprendizaje de lenguas. En teoría, el 56\% de europeos puede tener una conversación en al menos una lengua adicional. En torno al $40 \%$ habla inglés, pero solo $13 \%$ como lengua materna: es decir, los mensajes en inglés serían entendidos por una parte importante de la población europea.

12 Lanza y Woldemariam (2009) incluyeron en su estudio la presencia del inglés en Etiopía, lengua a la que se recurre en muchos casos, como los propios propietarios de los comercios mencionan, por las connotaciones asociadas a ella. Bogatto y Hélot (2010) analizan el Barrio de la Estación de Estrasburgo. Para la ciudad de Sevilla, véase Pons (2011). Para Madrid véase Castillo Lluch y Sáez Rivera (2011). Griffin (2001), quien ya había indicado la presencia del inglés en la publicidad polaca (1997), señala cómo el inglés es una lengua muy utilizada en procesos denominativos de tiendas en Sofía, y posteriormente llega a conclusiones similares en Roma (2004). Dimova se ocupa de Macedonia (2007). Para un estado general del inglés como lingua franca en Europa véase House (2008); un estudio general del PL anglófono de algunas ciudades europeas se encuentra Shclick (2002) y (2003). 
Con respecto a las lenguas que suelen combinarse con más frecuencia, encontramos que son español e inglés, en ese orden en el signo, seguidos por gran distancia de otras combinaciones. Esta combinación suele ser frecuente en menús, debido seguramente a la influencia del turismo. En textos claramente informativos como estos, de incluir una tercera lengua, lo más frecuente es el francés. El segundo esquema combinatorio más recurrente es español + italiano en restaurantes.

Hemos trabajado también con signos en español que presentan algunas interferencias con otras lenguas o variedades: son escasos y no llegan a la decena. Así, hemos percibido interferencias gráficas del inglés, como el uso de «my» por «mi», como ya hemos comentado (1). A veces, el valor simbólico de interferencia del uso de la lengua extranjera está en una adaptación gráfica que aproxime la voz española a otra lengua o en algún tipo de recreación. Así, hemos recogido interferencias en el uso de apóstrofo al final de palabras, a la manera del genitivo sajón, el signo tironiano, la utilización de la y griega en final de nombre (6) o el recurso a la $s$ líquida (7).

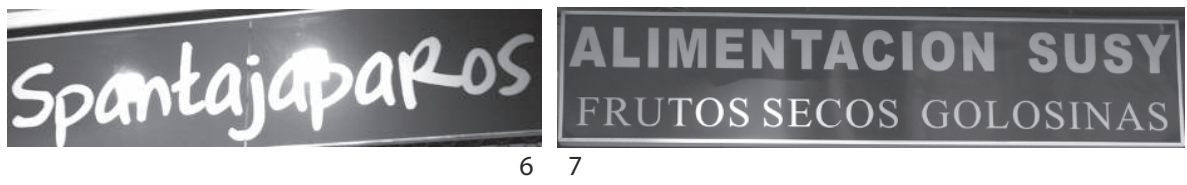

Hemos encontrado algunos ejemplos de interferencias con la variedad andaluza, pero no muy numerosos. En efecto, en el caso de Málaga, el inventario fonológico innovador, siguiendo ya sea el patrón seseante como el ceceante, es mucho menos frecuente que en la Andalucía occidental, especialmente en los hablantes más instruidos y en registros menos espontáneos (Villena Ponsoda y Ávila Muñoz 2012). Por ello, la transferencia de este fenómeno a textos escritos será previsiblemente menor de lo que puede serlo en otras hablas andaluzas.

Las muestras halladas se caracterizan por los siguientes rasgos: pérdida de la consonante posnuclear como rasgo más repetido (8); no solo de la $-s$, la más frecuente, sino también de la $-z$, en posición final de palabra, pero también en posición intermedia; como rasgos menos frecuentes, confusión de la lateral con la vibrante y grafías que presuponen producciones seseantes $\mathrm{y}$ ceceantes. Estas características aparecen en anuncios entre particulares, de

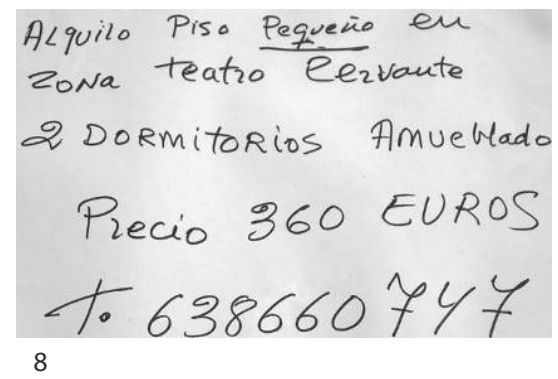


manera no premeditada; solo en una ocasión hemos encontrado un cartel que sí muestra un uso premeditado de la variedad andaluza en una taberna de tapas de corte andaluz (9). Como ya observó Pons (2011) para Sevilla, también en Málaga los autores andaluces crean textos con presencia deliberada de estos rasgos con el fin de que los negocios que anuncian adquieran sus connotaciones.
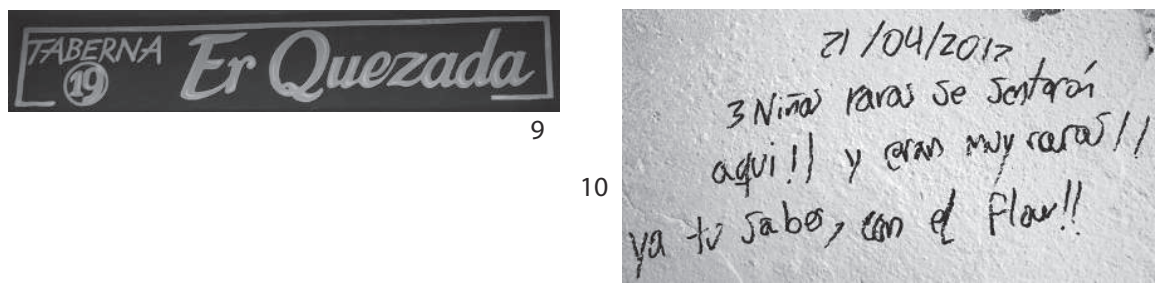

La presencia de trazas del patrón seseante en los textos escritos del PL malagueño puede relacionarse con más facilidad que en el caso sevillano con variedades hispanoamericanas. En cualquier caso, no hemos hallado una presencia significativa de este rasgo ni una copresencia con otras características lingüísticas americanas. Algunos textos presentan colocaciones y construcciones que no parecen frecuentes en español de España, especialmente en carteles entre particulares, pero no se combinan con la permeabilidad al patrón seseante. Hemos documentado también algunos grafitis (10) con estructuras propias del español caribeño del tipo «ya tú sabes» o «my brother» (en la zona multiétnica) (Ortiz López 1999).

En algunas ocasiones las lenguas extranjeras no aparecen combinadas, sino que son la única variedad presente en el signo estudiado. Que una lengua aparezca sola se explica por el hecho de que vaya dirigida a hablantes de esa comunidad lingüística o porque tiene el suficiente prestigio lingüístico para que así aparezca.

\begin{tabular}{|l|c|}
\hline \multicolumn{1}{|c|}{ Lengua $^{13}$} & $\begin{array}{c}\text { Número de signos en los que aparece sin } \\
\text { combinar con otras lenguas }\end{array}$ \\
\hline Inglés & 56 \\
\hline Ruso & 6 \\
\hline Latín & 2 \\
\hline Francés & 2 \\
\hline Griego & 1 \\
\hline Neerlandés & 1 \\
\hline Hindi & 1 \\
\hline Hebreo & 1 \\
\hline
\end{tabular}

13 Con el italiano surge un pequeño problema: la aparición en carteles de nombres que podrían ser españoles o italianos, es decir, voces que se podrían relacionar con ambas lenguas. Por eso, no lo hemos incluido en esta lista. 
La aparición autónoma del inglés se relaciona con una amplia tipología de textos: grafitis, anuncios entre particulares, rotulaciones de negocios (el grupo mayoritario, de aproximadamente la mitad de los signos), otros carteles de los negocios... (véase 11 y 12)

El hecho de encontrar grafitis en inglés puede dar cuenta de su vinculación con el movimiento urbano del último tercio del siglo $\mathrm{xx}$, vinculado al hip hop, que lo desarrolló especialmente. Algunos de los encontrados se relacionan con consignas de carácter internacional.

Sin embargo, la aparición aislada de otras lenguas solo se vincula a nombres de tiendas, excepción hecha por el ruso, que aparece en algunos de los carteles entre particulares que están en las vitrinas

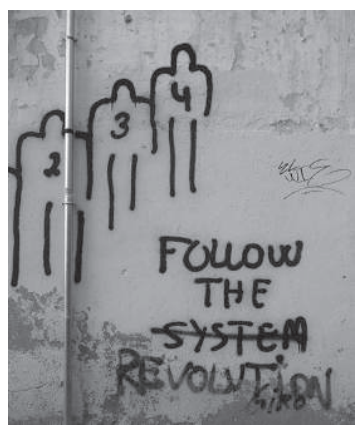

11

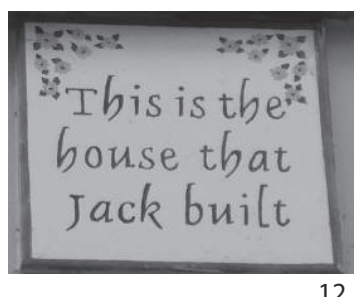
de un supermercado del centro de la ciudad. Es decir, exceptuando ese caso, no adquiere carácter informativo ninguna lengua aislada que no sea inglés.

Hemos realizado unas concordancias de los textos de todos los signos analizados. Eliminando las partículas, que son las voces más abundantes, los términos dotados de significado más frecuentes son los siguientes: day, gift, coffee, take (away), closed, house, bike, pizza, wine, shop, orange, open, lounge, juice, ice, free, art, fresh, free. La mayor parte de ellos son nombres concretos básicos en inglés, con valor eminentemente informativo, y se relacionan con negocios proyectados hacia el turismo: tiendas de regalos y restaurantes.

Otros son propios de denominaciones de establecimientos: parece una constante que muchos bares de noche utilicen el inglés para indicar el tipo de actividad que desempeña: music \& drinks (13), café lounge (14), music club (15), lounge \& club (16), gin selection (17), nights (18).

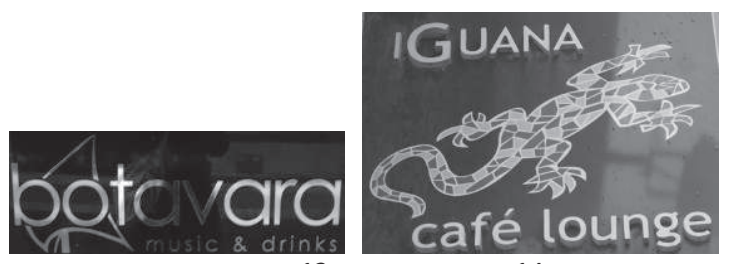

13
14

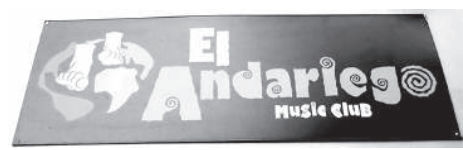

15 


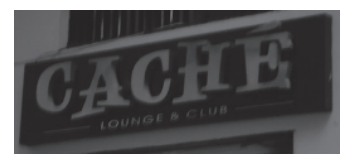

16

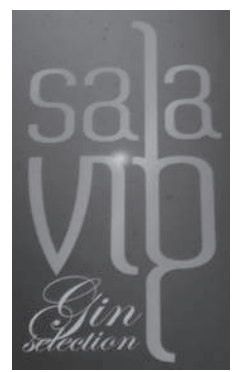

17

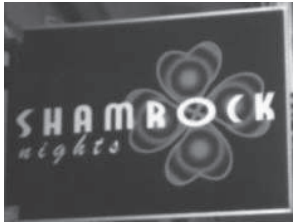

18

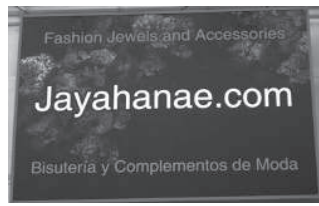

19

Barni, Bagna y Vedovelli (en prensa) están realizando una lista de italianismos presentes en el PL mundial. De los localizados en nuestra muestra, pizza, pasta, pizzería y espresso están recogidos; sin embargo, bruschetta, salami o verità, por ejemplo, no aparecen en la lista de los más populares.

\section{Prominencia visual}

El español, sin duda, domina todos los carteles plurilingües: es el que aparece en primer lugar en casi todos los ejemplos. Contamos con menos de una decena de excepciones: los menos se relacionan con un valor simbólico, como en 19, una tienda de bisutería que, con letras más pequeñas, a modo de antetítulo, indica la actividad del establecimiento, que vendrá traducida después del nombre de la empresa; la mayoría son textos claramente dirigidos a extranjeros que hablen inglés, por eso recurren a esta lengua en primer lugar en hoteles (20), alquiler de bicicletas (21) o carteles de empaquetado en ultramarinos (22).

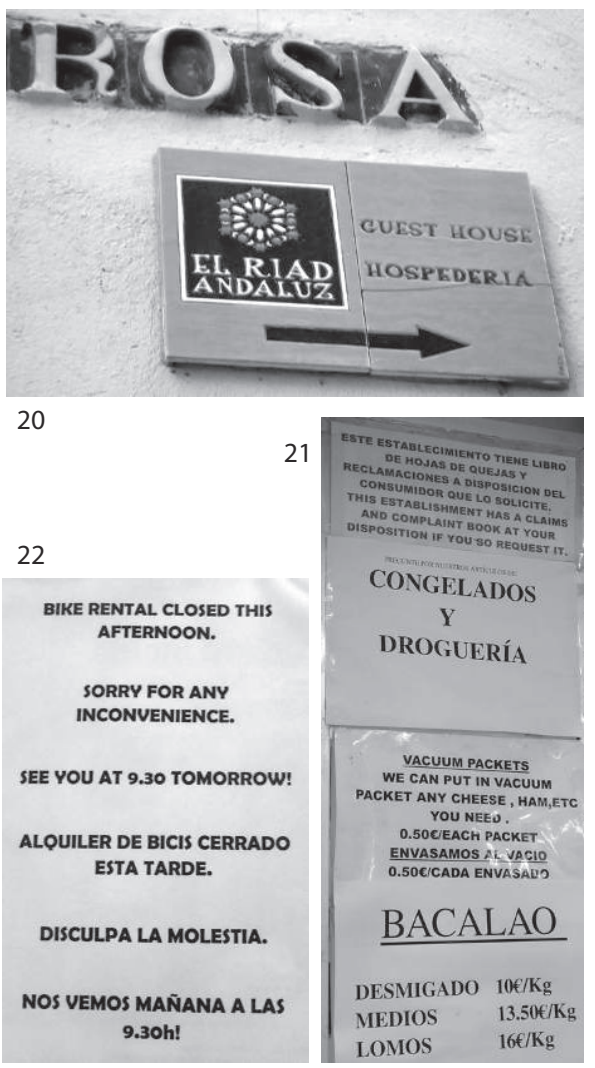




\section{Disponibilidad de traducción total o parcial}

La información multilingüe puede presentarse de tres formas diversas (Reh 2004): toda la información aparece en las dos lenguas, se hace una traducción parcial o se da una información diferente en cada idioma. El primer caso denota que nos dirigimos a hablantes monolingües de ambas lenguas: es lo que ocurre en los textos oficiales trabajados por Backaus en Tokio (2007). En nuestro corpus, 171 signos no encuentran traducción porque esperan que los lectores los comprendan (14), porque marcan simbólicamente el origen de la persona que los generó (15) o porque obedecen a procesos denominativos o de explicación de actividad comercial en todo tipo de establecimientos (16).

21 textos tienen traducciones parciales o muestran incluso significados diversos orientados a los públicos que leerán cada una de las lenguas. En 22 , se indican en inglés qué elementos son susceptibles de ser comprados y envasados al vacío en este establecimiento, para que los viajeros tengan conocimiento de ello, mientras que en español solo se señala que cabe la posibilidad de este tipo de envasado. En 23 se da la lista de desayunos en español y en inglés se añade que se dispone del desayuno inglés, que presuponen que será el demandado por los anglófonos. El texto de 24 nos parece realmente interesante, ya que se aclaran en inglés elementos culturales relativos a los efectos de hacer ruido en la calle, mientras que en la parte española prácticamente no se hace necesario añadir las consecuencias posibles de estos hechos. Este texto denota no solo lectores con conocimientos de lenguas diferentes, sino también una adaptación a los conocimientos culturales de los diferentes públicos.
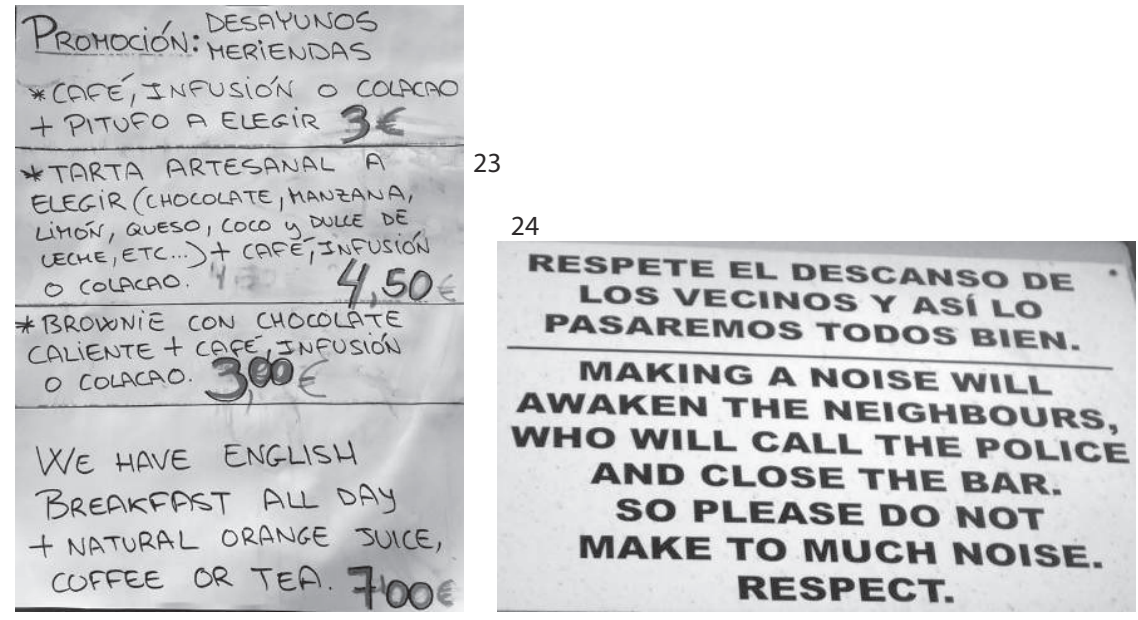
En 25 solo se traduce el tipo de negocio del que se trata.

Hay signos que presuponen un lector castellanoparlante que es capaz de entender ciertos términos en otras lenguas, por lo que se le traducen solo los elementos no transparentes (26).

Es un hecho: el mensaje plurilingüe malagueño no se presenta siempre como una confrontación perfecta de textos monolingües traducidos: a veces porque se le supone competencia al lector para acceder al significado, a veces porque al creador del texto le interesa resaltar informaciones diversas según los públicos y otras veces porque son signos de carácter simbólico.

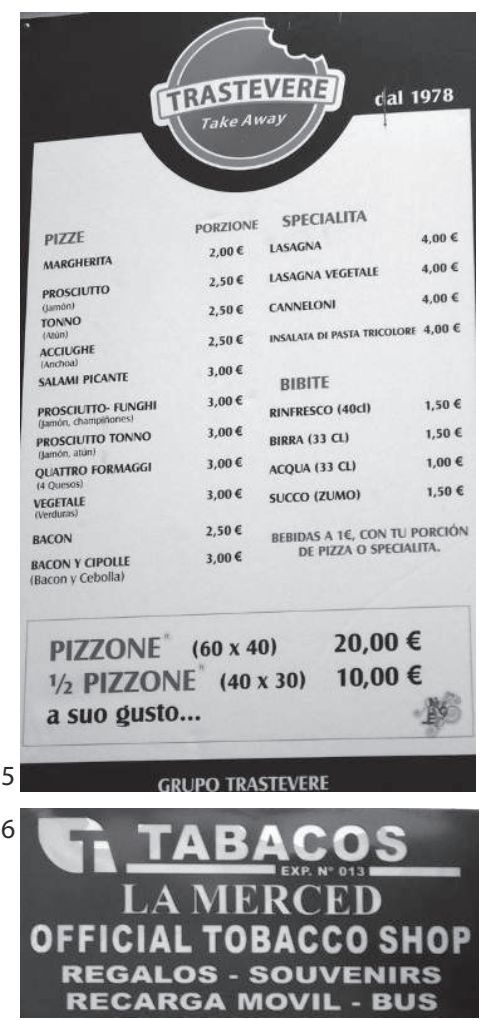

Carácter eminentemente simbólico o informativo del signo

Como dijeron Laundry y Bourhis (1997) el signo puede tener dos funciones: comunicar o, simplemente, ser símbolo. En comunidades multilingües la segunda función se puede añadir fácilmente a la primera: en comunidades definidas como monolingües, el hecho de que un signo pueda adquirir estos dos valores va a depender en gran medida del dominio lingüístico de la comunidad de receptores potenciales del mismo.

La mayoría de los signos monolingües que hemos trabajado son nombres de establecimientos o de sus actividades comerciales, que tienen un valor eminentemente simbólico, sin presuponer conocimientos profundos de la otra lengua, aunque en algunos casos, conocer la lengua del signo puede proporcionar pistas sobre su actividad comercial, con lo que atesoran también un valor informativo: ello ocurre en Vualá, Oyster Bar, un bar de ostras en el centro de la capital.

El nombre del establecimiento es la parte principal del texto, como indicó Franco-Rodríguez (2009), frente a una parte secundaria de carácter 
más informativo. Por ello, en nuestra tipología hemos separado carteles que solo tienen esa parte denominativa primera de aquellos que tienen los dos, y hemos encontrado lenguas extranjeras en ambas partes ${ }^{14}$.

El uso del inglés es un marcador de globalización. Es una lengua que se asocia con lo moderno, lo juvenil, lo cosmopolita, el éxito, el estatus social, el progreso, la diversión y la sofisticación, más que con una comunidad lingüística determinada: es la lengua de una élite moderna y sofisticada ${ }^{15}$. En tal caso se recurre, fundamentalmente, a lo que Haarmann (1986) llama «multilingüismo impersonal», que convierte en cool un signo sin más. Además, no hay que olvidar su presencia generalizada por su función como lengua franca internacional, lengua de comunicación que no se encuentra marcada desde el punto de vista geográfico, a la que se suele recurrir para transmitir mensajes a un público extranjero en general. Por todo ello, aparece en todo tipo de establecimientos.

El italiano aparece con valores asociados a Italia y su tradición culinaria y familiar (Acqua \& Farina, Mamma mia). Nombres propios o comunes

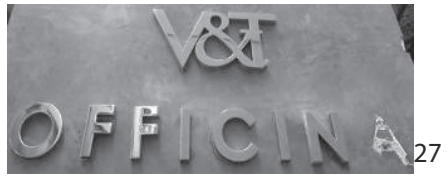

PAPIER ${ }^{28}$ italianos también se utilizan en ocasiones como sinónimos de moda, elegancia y estilo en la denominación de negocios de ropa: Sabochi; Officina (27); Scarpe di Ceisa, Roselli.

El francés también se asocia a la moda francesa, la alta costura, la belleza, al glamour y la exclusividad, también en restauración y decoración: Herbé Laurencin, Papier (28).

El árabe trasmite rememoranzas exóticas y es utilizado en los procesos denominativos de teterías y restaurantes (29). El griego se asocia también con una tradición culinaria milenaria, con una dieta equilibrada. En nuestra muestra solo tenemos un ejemplo de un nombre propio (30).

14 A la hora de clasificar las lenguas del PL supone un problema el hecho de trabajar con nombres propios, normalmente los nombres de empresas comerciales. Y es que los nombres propios tienden al multilingüismo, pero muchos podrían " pertenecer " a varias lenguas, como ya señaló Edelman (2009: 145). En tales casos, hemos tomado la óptica del público receptor hispanohablante, que podría ser diversa a la de otros públicos, y cuando una palabra puede ser interpretada como española por la comunidad receptora, como tal la hemos interpretado. Una segunda dificultad se desata al utilizar los nombres propios: es difícil diferenciar los que tienen carga semántica de los que no la tienen (Edelman 2009: 147). Por eso, nos hemos decantado por hablar de carteles con ambos valores siempre que era posible.

15 Estos valores añadidos a las lenguas se documentan también en la publicidad, como hemos analizado en Esteba Ramos (2009). 
El hebreo y el hindi tienen connotaciones religiosas: de hecho, las palabras recogidas en estas lenguas suelen estar en el campo semántico de la religión. Aparecen para denominar establecimientos. En el caso del hindi, puede utilizar una tipografía que recuerda el devanagari, pero no en todos los casos (31 y 32$)$.
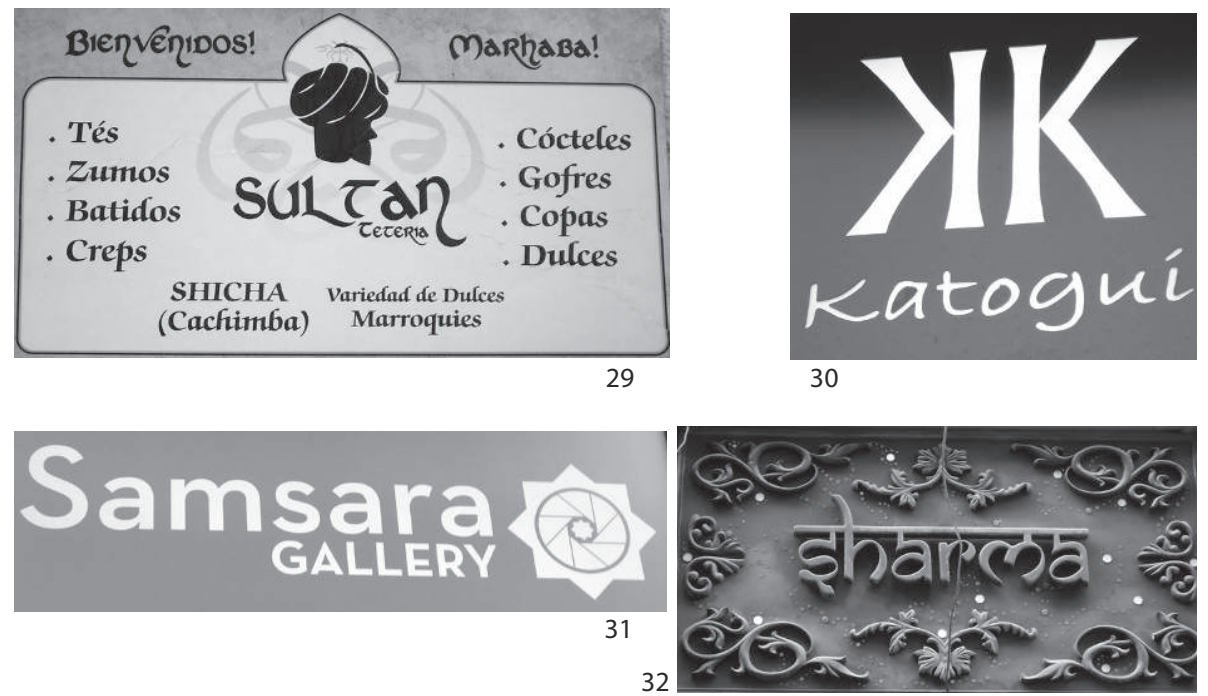

El alemán solo lo hemos documentado con valor informativo, así como el ruso, y las lenguas nórdicas. El neerlandés sirve en procesos denominativos de un establecimiento belga.

Una parte importante de nuestros signos plurilingües, cuando no proporcionan simplemente el nombre del establecimiento, parcela fundamentalmente simbólica, se encuentran traducidos. Ello es sin duda muestra del interés por que públicos con diferentes lenguas maternas puedan comprender el significado informativo de esta parte del signo, a pesar de que, como hemos señalado, las traducciones no son siempre literales.

Rotular solo en una lengua no transparente para los hispanohablantes con una intención claramente informativa supone un deseo de acercamiento a las personas competentes en esa lengua a la vez que construye una barrera lingüística infranqueable para aquellos que la desconozcan. Especialmente en el caso de la nominación comercial, si el valor denotativo simplemente aporta datos adicionales a la rotulación que se sirve de los valores asociados a la lengua utilizada, el problema será mínimo: el mensaje completo llegará a una parte de la población. La dificultad está en textos no denominativos 
que pueden utilizar de manera consciente esta práctica para restringir a sus destinatarios, lo que puede resultar altamente perjudicial por contribuir a la visión de comunidades cerradas, lo que podría evitarse a través de la traducción.

\section{Idiosincrasias lingüísticas}

Spolsky y Cooper (1991: 81-84), a modo de las máximas conversacionales de Grice, hablaron de los condicionantes que empujan a elegir una u otra lengua en los signos públicos: puede ser que escribas en la lengua que conoces; en la lengua que crees que hablan los que van a leer el texto (en este caso, es posible que se aprecien errores, como veremos a continuación) o puedes escribir en la lengua con la que te quieres ver identificado, es decir, buscas fundamentalmente un valor simbólico en la elección lingüística. Fijémonos en los dos últimos casos. Errores por desconocimiento de la lengua hemos documentado varios: algunos se han producido por intentar reproducir las características fonéticas a través de los sistemas ortográficos del español («gelatto» para "gelato», o «fock» por «fuck» en un grafiti; otros denotan ausencia de conocimientos morfológicos de la lengua (singular por plural en la mayor parte de los casos: «porzione» por «porzioni», «course» por «courses»; hay también errores ortográficos («coffe» por «coffee») y otros han ocurrido por intentar traducir literalmente un sintagma fijado en la lengua («red wine of summer» para «tinto de verano») .

En cuanto a la elección de una lengua simplemente por valores simbólicos, el caso más claro seguramente es el del árabe en las teterías o el del hindi en tiendas de productos de la India.

\section{Perspectivas}

En Shohamy y Gorter (2009), se habla, tal y como se recoge en el título, de la necesidad de que el PL expanda sus definiciones, sus componentes, sus interpretaciones, sus implicaciones y sus implementaciones. Por ello, ya que ese camino debe hacerse con pequeñas piedras que redefinan el mapa de actuación, ha sido y es nuestra intención proporcionar pequeños avances relacionados tanto con la primitiva investigación que acabamos de empezar a acometer como con la reflexión metodológica y teórica que puede ser aplicable a otros trabajos similares. Así, en cuanto al primer punto, ambicionamos ampliar la zona de análisis estudiada, con el fin de tener más datos sobre el paisaje lingüístico de la ciudad de Málaga que permitan hacer comparaciones con estudios de carácter global de otras ciudades. En 
lo que respecta al segundo punto, creemos que sería necesario concentrar la atención en revisar y definir con más precisión la tipología textual del signo público, objeto de estudio del PL (para la que hemos propuesto un esbozo de clasificación ad hoc aquí), además de expandir y desarrollar los potenciales que existen en el PL como poderosa herramienta para la educación.

En efecto, los estudios hasta ahora aparecidos han analizado fundamentalmente los signos para caracterizar la lengua de los espacios públicos, pero poco se ha analizado el poder de estos como fuentes de aprendizaje lingüístico. El valor del trabajo con el PL es evidente, ya que muestra la vida real de una lengua y puede ser una excelente manera de lograr la motivación de los estudiantes, tal y como han resaltado algunos textos en los que se explota el PL como arma en el camino hacia la alfabetización, hacia el conocimiento de una lengua extranjera o hacia la sensibilización lingüística y cultural en variedad de contextos ${ }^{16}$.

En cuanto a las aplicaciones en el ámbito de la docencia que nos compete, hemos considerado fundamentalmente dos ramas: utilización del PL en el aula de $\operatorname{ELE}^{17}$ y en el aula de asignaturas universitarias de grado relacionadas con el español normativo.

En los últimos años, a través del campus virtual, hemos sugerido a nuestros estudiantes, una vez proporcionados artículos sobre PL y muestras de signos malagueños, que ellos compartan fotografías con errores lingüísticos que encontraran en nuestra ciudad. El objetivo es identificar errores vinculados a los contenidos de la materia, además de proponer los cambios oportunos para la mejora del texto mediante la consulta de diccionarios de dudas y otros documentos recomendados ${ }^{18}$. En la era de las nuevas tecnologías, casi

16 Goodman (1984) observa las capacidades de los menores de 6 años para reconocer nombres, logotipos y direcciones en signos públicos; Huebner (2006) apunta a cómo el PL puede influir en la competencia lingüística de los jóvenes ciudadanos tailandeses y sus habilidades en thai e inglés; Dagenais, Moore, Sabatier, Lamarre y Armand (2009) tratan la conciencia sobre la diversidad lingüística de los niños a través del PL en contextos francófonos y anglófonos de Canadá, basándose en la motivación que despierta en los alumnos el hecho de fomentar el conocimiento a través del diálogo con el contexto inmediato; Shohamy y Waksman (2009) defienden la legitimidad del uso del PL en el aula por ser el "libro de texto" ideal donde se recogen conocimientos sobre la sociedad y la historia en la que se insertan; Malinowski $(2006,2010)$ presenta la unión de nuevas tecnologías y PL en el aula de lenguas extranjeras.

17 Proponemos actividades precisas para el aula de ELE en Esteba Ramos (en prensa).

18 Esta actividad ya había dado buenos resultados en años precios, ya que tareas semejantes se les pedían a los alumnos de la extinta Lengua de Publicidad y Relaciones Públicas, quienes debían localizar errores (organizados por niveles de análisis) y proponer las pertinentes mejoras en textos publicitarios. 
todos los estudiantes disponen de teléfonos móviles con cámara de fotos que les permiten capturar estas imágenes por la ciudad fuera del tiempo de clase, con lo que estamos proponiendo una tarea de fácil realización. Conseguimos con ello una concienciación sobre la necesidad de escribir textos correctos, además de una visión crítica hacia los textos públicos, que no siempre se encuentran exentos de errores. Logramos, en definitiva, que el alumno se implique y vincule la asignatura con aplicaciones prácticas, asentando las bases de un aprendizaje ubicuo y para toda la vida.

Dado que son tantas las voces del inglés que no encuentran traducción en el PL de nuestras ciudades, la rentabilidad en cursos de español normativo del grado de Estudios Ingleses es realmente grande. Los estudiantes deben cuestionarse la necesidad de aparición de estas palabras y las posibles opciones que ofrece la lengua castellana.

Puesto que, en nuestro caso, algunos textos dejan ver características propias de las hablas andaluzas, esta actividad podría trasladarse también sin esfuerzo al aula de asignaturas de Dialectología Meridional.

\section{Conclusiones}

El signo lingüístico público en el centro de Málaga es, sin duda, de carácter plurilingüe, ya que hemos documentado la presencia de más de una docena de lenguas. El inglés, solo o en combinación con otras lenguas, es, con mucha diferencia, el idioma más recurrente y no está siempre traducido, por lo que deducimos que con él en ocasiones se busca un valor simbólico apoyado en una base informativa. Aparece tanto en signos oficiales como en no oficiales, y lo hemos documentado en una gran variedad de tipos textuales, incluido el grafiti, mostrando una especial vinculación con tribus urbanas internacionales.

El inglés funciona en algunos textos como lengua general de comunicación con toda la comunidad extranjera, ya que en muchos signos informativos es la única lengua extranjera a la que se recurre. En otras ocasiones, se encuentra combinado con el francés. Es frecuente que se recurra a esta lengua para la denominación de establecimientos y actividades. De hecho, el plurilingüismo malagueño, incluso más allá del inglés, es deudor de la parte principal de los textos públicos, es decir, fundamentalmente obedece a la fijación de nombres de marcas o establecimientos, muchos de ellos multinacionales, o a las descripciones de los tipos de negocios, con un marcado carácter simbólico. 
Pocas interferencias dialectales hemos podido apreciar, relacionadas solo con algunos anuncios entre particulares y otros textos caracterizados por un alto grado de espontaneidad, cristalizadas estas interferencias básicamente en la pérdida de la -s final de palabra de las hablas andaluzas.

El patrón más frecuente analizado ha sido el del monopoly, seguido por el moteado. A pesar de que incluimos en nuestro análisis calles de transición a zonas multiétnicas, no ha sido significativo este dato en el PL recogido, y no podemos hablar de una clara identificación del patrón boca del lobo, puesto que parece que la población inmigrante de la zona deja una influencia escasa en las realidades lingüísticas. Estaríamos, más bien, ante un patrón silencioso o silenciado.

En suma, hemos diseccionado una pequeña porción del centro de esta ciudad turística andaluza que nos ha dado pistas sobre el interés que puede esconderse en esta localidad desde el punto de vista del PL. Sería deseable contar con un estudio más abarcador para poder proporcionar datos complementarios a la descripción de la situación lingüística malagueña y poder realizar comparaciones pertinentes con el PL de otras ciudades hispanohablantes, así como para llevar a cabo mayores aplicaciones didácticas de las que hemos presentado.

\section{Bibliografía}

Backhaus, P., 2006, «Multilingualism in Tokio: A look into the linguistic landscape», International Journal of Multilingualism 3(1), p. 52-66.

Backhaus, P., 2007, Linguistic Landscapes: A Comparative Study of Urban Multilinguilism in Tokyo, Clevedon, Buffalo, Toronto, Multilingual Matters.

Bagna, C, M. Barni y M. Vedovelli, sous presse, «Italianismi e pseudoitalianismi nella comunicazione pubblica/sociale planetaria», in L. Serianni (ed), L'Italiano nel mondo, Turin, UTET.

Bagna, C. y M. Barni, 2009, "A Mapping Technique and the Linguistic Landscape», in E. Shohamy y D. Gorter (eds.), Linguistic Landscape: Expanding the Scenery, Nueva York, Routledge, p. 126-140.

Ben-Rafael, E. et al., 2006, «Linguistic Landscape as Symbolic Construction of the Public Space: The Case of Israel», International Journal of Multilingualism, 3: 7-30 http://www.informaworld.com/smpp/title $\sim \mathrm{db}=\mathrm{all} \sim$ content $=\mathrm{t} 794020038 \sim \mathrm{tab}=\mathrm{iss}$ ueslist $\sim$ branches $=3-\mathrm{v} 3$

Ben-Rafael, E. et al., 2010, "A sociological approach to the study of Linguistic Landscapes», Linguistic landscape in the city, Clevedon, Buffalo, Toronto, Multilingual Matters, p. 40-54. 
Bogatto, F. y C. Hélot, 2010, «Linguistic Landscape and Language Diversity in Strasbourg: The "Quartier Gare"», in E. Shohamy, E. Ben-Rafael, y M. Barni (eds.), Linguistic Landscape in the City, Bristol, Multilingual Matters, 275-291.

Castillo Lluch, M. y D. M. Sáez Rivera, 2011, «Introducción al paisaje lingüístico de Madrid», Lengua y Migración, 3, p. 73-88.

Cenoz, J. y D. Gorter, 2006, «Linguistic Landscape and Minority Languages». International Journal of Multilingualism: 3: 67-80.

Dagenais, D. et alii, 2009, "Linguistic landscape and language awareness», in E. Shohamy y D. Gorter (eds.), Linguistic Landscape: Expanding the Scenery, Nueva York, Routledge, p. 253-269.

Dimova, S., 2007, «English shops in Macedonia», English Today, p. 18-24.

Edelman, L., 2009, «What's in a name? Classification of Proper Names by Language», en E. Shohamy y D. Gorter (eds.), Linguistic Landscape: Expanding the Scenery, Nueva York, Routledge, p. 141-154.

Eder, K., 2006, «Making sense of the public sphere», en G. Delanty (ed.) Handbook of Contemporary European Social Theory, London, Routledge, p. 333-346.

Esteba Ramos, D., 2010, «La publicidad española, ¿monolingüe?», Círculo de Lingüística Aplicada a la Comunicación 41, p. 31-55.

Esteba Ramos, D., (sous presse), «¿Qué te dice esta ciudad? Modelos de reflexión y propuestas de actuación en torno al paisaje lingüístico en la clase de Español Lengua Extranjera», XIII Simposio Internacional de Comunicación Social (SICS / ISSC), Universidad de Santiago de Cuba, janvier 2013.

Extra, G. y D. Gorter, 2008, «The constellation of languages in Europe: an inclusive approach» in Multilingual Europe: Facts and Policies, Berlín-Nueva York, Mouton de Gruyter, p. 3-62.

Franco Rodríguez, J. M., 2008, «El paisaje lingüístico del Condado de Los Ángeles y del Condado Miami Dade: propuesta metodológica», Círculo de Lingüística Aplicada a la Comunicación, 35.

Franco Rodríguez, J. M., 2009, «Interpreting the Linguistic Traits of Linguistic Landscapes as Ethnolinguistic Vitality: Methodological Approach», Revista Electrónica de Lingüística Aplicada, 8, p. 1-15.

Goodman, Y., 1984, «The Development of Initial Literacy», en Goelman, Hillel, Antoinette Oberg \& Frank Smith (eds.) Awakening to literacy, Portsmouth, Nh, Heinemann Educational Books, Londres, p. 102-109.

Gorter, D., 2006, «Introduction: The study of the linguistic landscape as a new approach to multilingualism» International Journal of Multilingualism, 3(1), p. 1-6.

Griffin, J., 1997, «Global English envides Poland», English Today, p. 34-39.

Griffin, J., 2001, «Global English infiltrates Bulgaria», English Today, p. 54-60.

Griffin, J., 2004, «The presence of written English on the streets of Rome», English Today, p. 3-8. 
Haarmann, H., 1986, «Verbal strategies in Japanese fashion magazines», International Journal of the Sociology of Language, 58, p. 107-121.

Hélot, C., M. Barni, R. Janssens y C. Bagna (sous presse), Linguistic Landscapes, Multilingualism and Social Change: Diversité des approaches, Bern, Peter Lang.

House, J., 2008, «English as lingua franca in Europe today», in Multilingual Europe: Facts and Policies, Berlin-New York, Mouton de Gruyter, p. 63-85.

Huebner, T., 2006, «Bangkok's linguistic landscapes: Environmental print, codemixing, and language change» in D. Gorter (ed.), Linguistic Landscape: A New Approach to Multilingualism, Clevedonm Multilingual Matters, p. 31-51. [y también International Journal of Multilingualism 3(1), p. 31-51].

Landry, R. y R. Y. Bourhis, 1997, "Linguistic landscape and ethnolinguistic vitality: an empirical study», Journal of Language and Social Psychology, 6, p. 23-49.

Lanza, E. y H. Woldemariam, 2009, «Language Ideology and Linguistic Landscape: Language Policy and Globalization in a Regional Capital of Ethiopia», in E. Shohamy y D. Gorter (eds.), Linguistic Landscape: Expanding the Scenery, Nueva York, Routledge, p. 189-205.

Leprêtre Alemany, M. y J. M. Romaní Olivé, 2000, «L'ús de les llengües a la publicitat exterior a Barcelona i a sis altres ciutats l’any 1999», in Llengua i ús: revista tècnica de política lingüística, 17, p. 55-59.

<http://www.raco.cat/index.php/LlenguaUs/article/view/129181/178198>

Malinowski, D., 2006, «Making Culture in Place: The creation of an online KoreanEnglish forum to discuss the offline linguistic landscape», Language Teaching at Berkeley, vol. 21.

Malinowski, D., 2009, "Authorship in the Linguistic Landscape: A Multimodal Performative View», in E. Shohamy y G. Durk (eds.), 2009, Linguistic Landscape Expanding the scenery, New Cork, Routledge, p. 107-125.

Malinowski, D., 2010, "Showing seeing in the Korean linguistic cityscape», in E. Shohamy, E. Ben-Rafael y M. Barni (eds.), Linguistic Landscape in the City, Bristol, Multilingual Matters, p. 199-215.

Masai, Y., 1972, Tokyo no Seikatsu Chizu [Living Map of Tokyo]. Tokio, Jiji Tsushinsha.

Mondada, L., 2000, Décrire la ville, París, Édition Payot et Rivages.

Ortiz López, L. A. (ed.), 1999, El Caribe hispánico: perspectivas lingüísticas actuales, Frankfurt, Vervuert, Madrid, Iberoamericana.

Pons Rodríguez, L., 2011, «Hispanoamérica en el Paisaje Lingüístico de Sevilla», Itinerarios, vol. 13, p. 97-129.

Pons Rodríguez, L., (sous presse): El paisaje lingüístico de Sevilla, Sevilla, Diputación de Sevilla.

Reh, M. 2004, «Multilingual writing. A reader-oriented typology -with examples from Lira Municipality (Uganda)», in International Journal of the Sociology of Language, 170, p. 1-41. 
Shclick, M., 2002, «The English in shop signs in Europe», English Today, p. 3-7.

Shclick, M., 2003, «The English in shop signs in Europe», English Today, p. 3-17.

Shohamy, E., E. Ben-Rafael y M. Barni (eds.), 2010, Linguistic landscape in the city, Clevedon, Buffalo, Toronto, Multilingual Matters.

Shohamy, E. y D. Gorter (eds.), 2009, Linguistic Landscape Expanding the scenery, New Cork, Routledge.

Solé i Camardons, J., 1998, "La llengua de la publicitat exterior a Barcelona», Llengua i ús: Revista tècnica de política lingüística, 12, 49-53. http://www.raco.cat/index. php/LlenguaUs/article/view/129541/178956

Spolsky, B. y R. L. Cooper, 1991, The languages of Jerusalem, Oxford, Clarendon.

Tulp, S.M., 1978, Reklame en tweetaligheid: Een onderzoek naar de geografische verspreiding van franstalige en nederlandstalige affiches in Brussel. Taal en sociale integratie 1, p. 261-288.

Urrutia Libarona, I., 1999, «El régimen jurídico del paisaje lingüístico en Euskal Herria», Revista Vasca de Administración Pública. Herri-Arduralaritzako Euskal Aldizkaria, 54, p. 357-404.

Villena Ponsoda, J. A. y A. M. Ávila Muñoz (eds.), 2012, Estudios sobre el español de Málaga. Pronunciación, vocabulario y sintaxis, Málaga, Sarriá. 